\title{
MORPHOMETRY OF ACROMION PROCESS OF HUMAN SCAPULAE
}

Vinay KV ${ }^{* 1}$, Aravind $U^{2}$, Sangeetha DM ${ }^{3}$, Arathy LN ${ }^{2}$.

${ }^{* 1}$ Professor of Anatomy, A.J Institute of Medical Sciences, Kuntikana, Mangaluru, Karnataka, India.

${ }^{2}$ Second year MBBS student, K.S. Hegde Medical Academy, NITTE (Deemed to be University) Deralakatte, Mangaluru, Karnataka, India.

${ }^{3}$ Associate Professor, A.J. Institute of engineering and technology, Mangaluru, Karnataka, India.

\section{ABSTRACT}

Background: The acromion process plays an important role in formation of the shoulder joint and provides stability to the shoulder joint. Acromion process resection is done in case of shoulder impingement syndrome.

Materials and Methods: About 100 dry human scapulae were measured for parameters such as length, breadth of acromion process of scapula. The acromio coracoids distance and acromio glenoid distance was measured using vernier callipers.

Observation: It was observed that the curved type of acromion process was the commonest type. Flat type is least common type. The mean length of acromion process on right side is longer significantly than the left side. The length of acromion process on right side is significantly longer than the left side. All the other parameters (Breadth of acromion process, Acromio glenoid distance, acromio clavicular distance on right and left side was not significant.

Conclusion: The present study provides useful data of dimensions of acromion which may help the orthopaedicians during surgical repair around the shoulder joint. It will of interest to anthropologists when studying about the evolution of the bipedal gate.

KEY WORDS: Scapula, Acromion process, Coracoid process, Morphometry.

Corresponding Author: Dr. Vinay KV, Professor of Anatomy, A.J Institute of Medical Sciences, Kuntikana, Mangaluru. Karnataka. India. Mob: 7795767676. E-Mail: dr7795767676@gmail.com

Access this Article online

Quick Response code

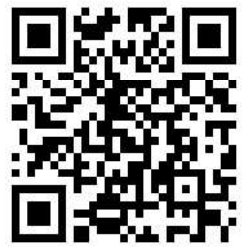

DOI: $10.16965 /$ ijar.2019.364

Journal Information

International Journal of Anatomy and Research

ICV for 2016 ISSN (E) 2321-4287 | ISSN (P) 2321-8967

90.30 https://www.ijmhr.org/ijar.htm

DOI-Prefix: https://dx.doi.org/10.16965/ijar

Article Information

Received: 07 Dec 2019

Peer Review: 09 Dec 2019

Revised: None
Accepted: 05 Jan 2020

Published (O): 05 Feb 2020

Published (P): 05 Feb 2020

\section{INTRODUCTION}

The acromion process plays an important role in formation of the shoulder joint and provides stability to the shoulder joint. Acromion process resection is done in case of shoulder impingement syndrome.

The coraco-acromial arch is formed by the coracoid process, coraco- acromial ligament and acromion process [1]. This arch is fairly a non- elastic structure. The rotator cuff tendons, sub acromial bursa and biceps tendon will pass beneath this arch [2].
Mechanical impingement is caused if the space available is narrowed either due to acquired or congenital causes. As the acromion process is commonly involved in impingement syndrome of shoulder joint the knowledge about morphometry of acromion process is important. The anatomical cause for impingement syndrome is the shape and inclination of the acromion [3]. The slope and length of the acromion and height of the arch are most closely associated with degenerative changes [4].

The knowledge about the various shapes \& 
dimensions of the acromion process will help the orthopaedicians during surgical repair around the shoulder joint. It would also be useful for anthropologists studying about the evolution of the bipedal gait.

Various studies have been conducted on the morphology of the acromion process of the scapulae. The association between acromion morphology, shoulder impingement and rotator cuff tears has been well documented.

Bigliani describes three main types of acromion morphology: Type-1- Flat; Type-2- Curved and Type-3- Hooked with relative percentages of $8.6 \%, 42.0 \%$ and $38.6 \%$ respectively. It is widely accepted that rotator cuff lesions are noticed mainly in the hooked acromion. (62.66\% of the cases of rotator cuff rupture involve the type III acromion) [5].

The understanding of the anterior one third of the acromion was pinpointed by Neer CS as the area responsible for impinging upon the components of rotator cuff. He also noted a characteristic ridge of spurs on the anterior acromion process [6].

Edelson JG performed various measurements in 200 scapulae and concluded that the slope and length of the acromion and the height of the arch are most closely associated with degenerative changes [7].

Ciochon RL devised two measurements, the coracoacromial projection index and the height of the glenoid cavity in Hominoida, Cercopithecoidea and Ceboidea and showed that hominoid shoulder joints are much more mobile than cercopithecoid shoulder joints [8].

Farley TE proposed a classification which includes a fourth type of acromion, which is concave downward. This classification has not gained much acceptance, mainly owing to the very small incidence of this type of acromion (1.6-13.3\%) and the absence of correlation with rotator cuff pathology [9]. The shape, dimensions of acromion process, the acromio coracoids distance and acromio glenoid distance of scapula were measured.

\section{MATERIALS AND METHODS}

This cross-sectional study was done on 100 dry human scapulae bones that were collected from first MBBS students and Anatomy department library collections.

The following parameters were measured with the help of a digital Vernier Calliper and a measuring tape:

Length of acromion process (LAP): the distance between tip and midpoint of posterior border of acromion process. (Figure 1)

Breadth of acromion process (BAP): the distance between the lateral and medial borders at the midpoint of the acromion process. (Figure 2)

Acromio-coracoid distance (ACD): the distance between tip of acromion process and tip of coracoid process. (Figure 3)

Acromio-glenoid distance (AGD): the distance between tip of Acromion process and supraglenoid tubercle. (Figure 4)

The results were tabulated \& analyzed statistically. The mean \& standard deviation was calculated. The parameters were compared between right \& left side for significance using Student's $t$ test. The level of significance was set at $p<0.05$. The data was analyzed using SPSS version 16.0 (SPSS Inc., Chicago, IL, USA).

Fig. 1: Measuring the Length of Acromion process (LAP).

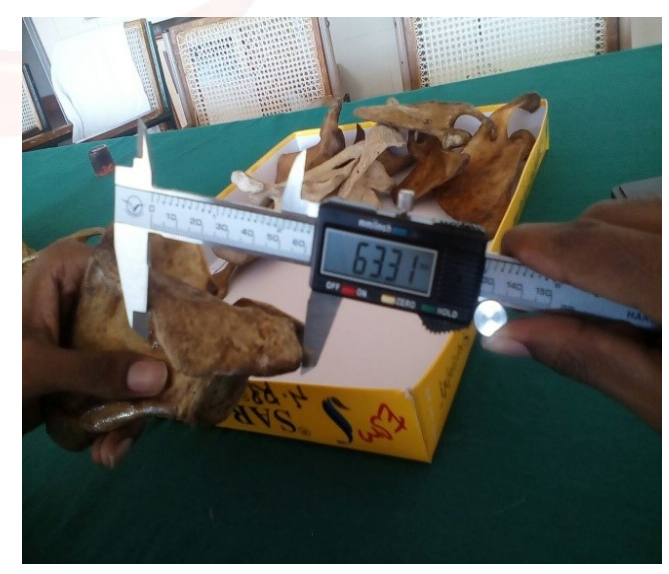

Fig. 2: Measuring breadth of Acromion process (BAP).

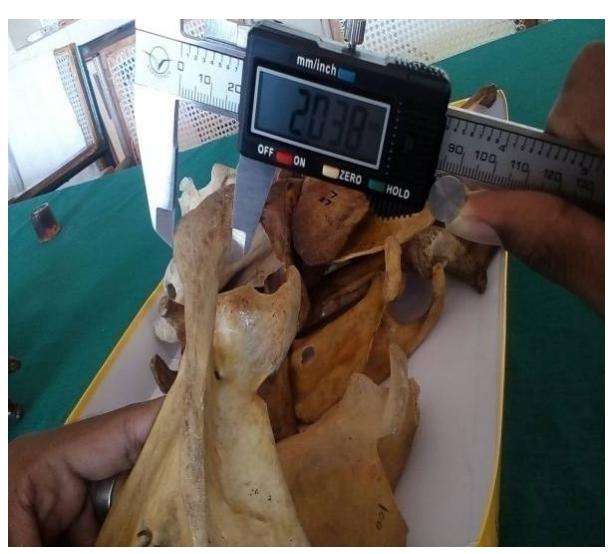


Fig. 3: Measuring the Acromio- Coracoid distance (ACD).

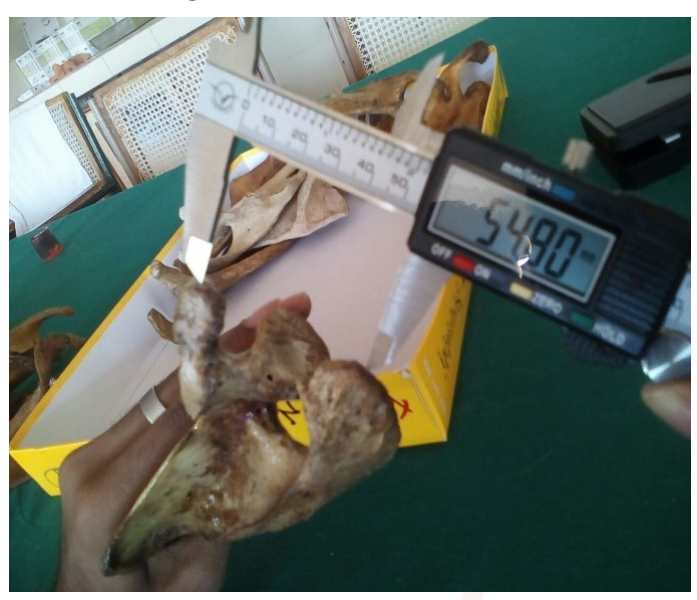

Fig. 4: Measuring the Acromio Glenoid distance (AGD).

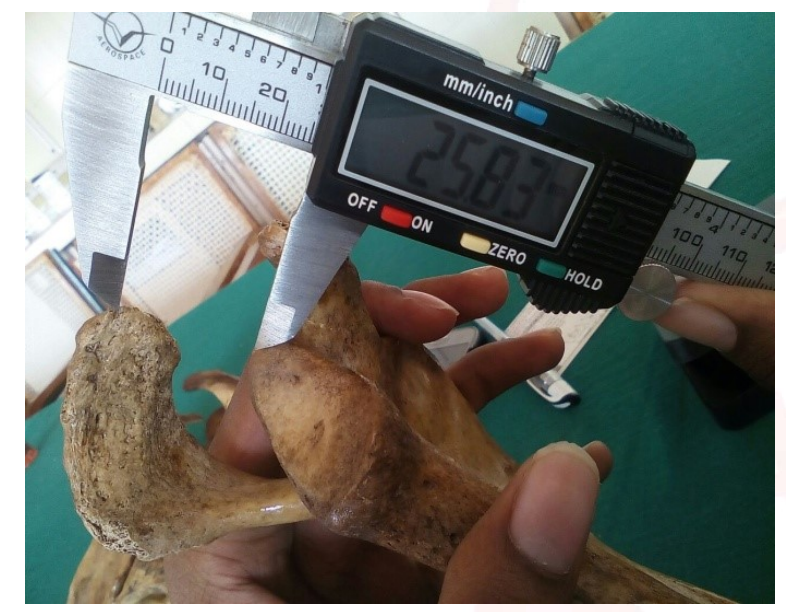

\section{RESULTS}

The curved type of acromion process was most common $49 \%$ followed by hooked type (42\%). The least type was flat type of acromion process (9\%) (Table 1).

The mean LAP (Table 2 ) on right side \& left side was $48.76 \mathrm{~mm}$ (40.61 to $63.31 \mathrm{~mm}$ ) and $45.50 \mathrm{~mm}$ (31.85 to $60.23 \mathrm{~mm}$ ) respectively. It was observed that the LAP on right side was more than LAP on left side by $3.29 \mathrm{~mm}$. On comparing LAP on right and left side it was found to be statistically significant.

The mean BAP (Table 2) on right side \& left side was $27.43 \mathrm{~mm}$ ( 20.51 to $35.81 \mathrm{~mm}$ ) and 26.67 $\mathrm{mm}(16.41$ to $33.87 \mathrm{~mm})$ respectively. On comparison BAP on right and left side it was found to be not statistically significant.

The mean ACD (Table 3 ) on right side \& left side was $38.26 \mathrm{~mm}$ ( 24.53 to $54.8 \mathrm{~mm}$ ) and 37.17 $\mathrm{mm}$ (26.63 to $49.7 \mathrm{~mm}$ ) respectively. On comparison ACD on right and left side it was found to be not statistically significant.

The mean AGD (Table 3) on right side \& left side was $27.62 \mathrm{~mm}(18.89$ to $38.17 \mathrm{~mm})$ and $27.14 \mathrm{~mm}$ (19.21 to $37.1 \mathrm{~mm}$ ) respectively. On comparison AGD on right and left side it was found to be not statistically significant.

Table 1: Shape of acromion process of scapula.

\begin{tabular}{|c|c|c|c|}
\hline Shape & $\begin{array}{c}\text { Right } \\
\text { Percentage }\end{array}$ & $\begin{array}{c}\text { Left } \\
\text { Percentage }\end{array}$ & $\begin{array}{c}\text { Total } \\
\text { Percentage }\end{array}$ \\
\hline $\mathbf{n}$ & 45 & 55 & 100 \\
\hline Curved & $22(48.88 \%)$ & $27(49.09 \%)$ & $49(49 \%)$ \\
\hline Flat & $4(8.88 \%)$ & $5(9.09 \%)$ & $9(9 \%)$ \\
\hline Hooked & $19(42.22 \%)$ & $23(41.81 \%)$ & $42(42 \%)$ \\
\hline
\end{tabular}

Table 2: Length (LAP) \& Breadth (BAP) of acromion process of scapula.

\begin{tabular}{|c|c|c|c|c|}
\hline & $\begin{array}{c}\text { LAP Right } \\
(\mathbf{m m})\end{array}$ & $\begin{array}{c}\text { LAD Left } \\
(\mathbf{m m})\end{array}$ & $\begin{array}{c}\text { BAP Right } \\
(\mathbf{m m})\end{array}$ & $\begin{array}{c}\text { BAP Left } \\
(\mathbf{m m})\end{array}$ \\
\hline $\mathrm{n}$ & 45 & 55 & 45 & 55 \\
\hline Mean & 48.76 & 45.5 & 27.43 & 26.67 \\
\hline Maximum & 63.31 & 60.23 & 35.81 & 33.87 \\
\hline Minimum & 40.61 & 31.85 & 20.51 & 16.41 \\
\hline Standard deviation & 4.86 & 5.79 & 3.51 & 3.56 \\
\hline P value & $\begin{array}{c}0.003 \text { Statistically } \\
\text { Significant }\end{array}$ & \multicolumn{2}{|c}{0.29 Not significant } \\
\hline
\end{tabular}

Table 3: Acromio clavicular distance (ACD) \& Acromioglenoid distance (AGD) in Scapula.

\begin{tabular}{|c|c|c|c|c|}
\hline & ACD Right & ACD Left & AGD Right & AGD Left \\
\hline $\mathrm{n}$ & 45 & 55 & 45 & 55 \\
\hline Mean & 38.26 & 37.17 & 27.62 & 27.14 \\
\hline Maximum & 54.8 & 49.7 & 38.17 & 37.1 \\
\hline Minimum & 24.53 & 23.63 & 18.89 & 19.21 \\
\hline Standard deviation & 5.94 & 5.85 & 3.99 & 3.58 \\
\hline Pvalue & \multicolumn{2}{|c|}{0.36 Not significant } & \multicolumn{2}{|c|}{0.53 Not significant } \\
\hline
\end{tabular}

\section{DISCUSSION}

Various studies have been conducted on the morphology of acromion process of the scapulae. The association between acromion morphology, shoulder impingement and rotator cuff tears has been well documented.

According to the Bigliani, three main types of acromion morphology have been described: Type-1(flat); Type-2 (curved) and Type-3(hooked) with relative percentages of $8.6 \%, 42.0 \%$ and $38.6 \%$ respectively. It is widely accepted that rotator cuff lesions are noticed mainly in the hooked acromia ( $66 \%$ of the cases of rotator cuff rupture involve the type III acromion) $)^{5}$. In the present study also Type 2 (Curved) was the commonest type (Table 1). This was similar to other studies done by Mansur DI [3].

Type III (Hooked) acromion process which is known to cause impingement syndrome was 
found in $42 \%$ which is higher than that was observed by others $[3,5]$.

In the present study, the LAP was 48.76 and 45.5 $\mathrm{mm}$ on right and left side respectively. The LAP of present study was higher than the study done on Napalese scapulae [3] (46.46 mm on right and $45.57 \mathrm{~mm}$ on left side), less than Egyptian scapulae ${ }^{10}(52.81 \mathrm{~mm})$ and Chilean scapulae (69.12 mm) [11].

In the present study, the mean BAP was $27.43 \mathrm{~mm}$ on right and $26.67 \mathrm{~mm}$ on left side which was comparable to BAP of right and left scapula ( $26.63 \mathrm{~mm} 27.23 \mathrm{~mm}$ ) in study done by Mansur DI [3].

The chances of impingement syndrome is more where the subacromion space is less [2]. The The AGD, coracoacromion, and coracoglenoid distances measure the subacromion space. The AGD in the present study was $27.62 \mathrm{~mm}$ and $27.14 \mathrm{~mm}$ on right and left side respectively. AGD was $28.28 \mathrm{~mm}$ [12], $31 \mathrm{~mm}$ in Napalese scapu$\mathrm{lae}^{3}, 28.43 \mathrm{~mm}$ in Chilean scapulae [11] and $27.39 \mathrm{~mm}$ in Egyptian scapulae [13].

The ACD corresponds to length of coracoacromion ligament. Resection of coracoacromion ligament without acromioplasty provides significant relief in pain of a patient with impingement. Resection of coracoacromion ligament may cause instability of Humerus [14].

The ACD on right side \& left side was $38.26 \mathrm{~mm}$ and $37.17 \mathrm{~mm}$ in the present study. On comparing with other studies ACD of present study was found to be higher than ACD in Napalese scapulae [3] (26.63 mm), Egyptian [13], Greek scapula [2] and study done by Sinha BM et al. (35.94) [12]. The ACD of present study was lower than ACD among Chilean scapulae $(39.76 \mathrm{~mm})$ [11].

\section{CONCLUSION}

The curved type of acromion process is the commonest type. Flat type is least common type. The mean length of acromion process on right side is significantly longer than the left side which may be due to the fact that majority are right handed persons. All the other parameters (Breadth of acromion process, Acromio glenoid distance, acromio-clavicular distances) on right and left side were not statistically significant.
The present study provides useful database on dimensions of acromion process of scapula which helps the orthopaedicians during surgical repair around the shoulder joint. It also helps anthropologists in studying about the evolution of the bipedal gate. The clinical significance of this study rests on the causative effect of the shape of the acromion in relation to the impingement syndrome as well as to rotator cuff rupture. The percentage of hooked type acromion process was found in $42 \%$ of cases which is the major causative factor for impingement syndrome when compared with other studies. The study sample size can be increased to get an overall idea about the dimensions of scapulae among Indian population.

\section{ACKNOWLEDGEMENTS}

We are thankful to department of Anatomy for allowing us to study dry bone from department collections.

\section{Conflicts of Interests: None}

\section{REFERENCES}

[1]. Singh J, Pahuja K, Agarwal R. Morphometric parameters of the acromion process in adult human scapulae. Indian J Basic Appl Med Res. 2013; 8(2): 116570.

[2]. Paraskevas G, Tzaveas A, Papaziogas B, Kitsoulis P, Natsis K, Spanidou S. Morphological parameters of the acromion. Folia Morphologica. 2008; 67(4): 255- 260.

[3]. Mansur DI, Khanal K, Haque MK, Sharma K. Morphometry of acromion process of Human Scapulae and its Clinical Importance Amongst Nepalese Population. Kathmandu Univ Med J. 2012; 38(2): 33-36.

[4]. Edelson JG, Taitz C. Anatomy of the coraco-acromial arch. Relation to degeneration of the acromion. J Bone Joint Surg Br. 1992; 74: 589-594.

[5]. Bigliani LU, Morrison DS, April EW. The morphology of the acromion and rotator cuff impingement. Orthop Trans. 1986; 10: 228.

[6]. Neer CS. Anterior acromioplasty for the chronic impingement syndrome in the shoulder. J Bone Joint Surg (Am). 1972; 54: 41-50.

[7]. Edelson JG, Zuckerman J, Hershkovitz I. Osacromiale: anatomy and surgical implications. J of Bone and Joint Surgery Br. 1993; 75: 551-555.

[8]. Ciochon RL, Corruccini RS. The coraco-acromial ligament and projection index in man and other anthropod primates. J Anat. 1977; 124 (3): 627-632.

[9]. Farley TE, Neumann CH, Steinbach LS, Petersen SA. The coracoacromial arch: MR evaluation and correlation with rotator cuff pathology. Skeletal Radiol. 1994; 23: 641-645. 
[10]. Vinay G, Sivan Sheela. Morphometric study of the acromion process of scapula and its clinical importance in South Indian population. Int J Anat Res. 2017; 5 (3.3): 4361-436410.

[11]. Collipal E, Silva H, Ortegal L, Espinoza E, Martinez C. The acromion and its different forms. Inter J Morphol. 2010; 28(4): 1189-1192.

[12]. Sinha MB et al., The acromial morphology and its implication in impingement syndrome: An anatomical study. Journal of the Anatomical Society of India. 2018, 67: 30-34.
[13].El-Din Wael Amin Nasr, Ali Mona Hassan Mohammed. A morphometric study of the patterns and variation of the acromion and glenoid cavity of the scapulae in Egyptian population. J Clin Diagn Res. 2015; 9(8): 8-11.

[14]. Su WR, Budoff JE, Luo ZP. The effect of coracoacromial ligament excision and acromioplasty on superior and anterosuperior glenohumeral stability. Arthroscopy. 2009; 25(1): 13-8.

How to cite this article:

Vinay KV, Aravind U, Sangeetha DM, Arathy LN. MORPHOMETRY OF ACROMION PROCESS OF HUMAN SCAPULAE. Int J Anat Res 2020;8(1.2):7311-7315. DOI: 10.16965/ijar.2019.364 